\title{
PENERAPAN TIPOGRAFI DALAM SISTEM SIGNAGE PADA INTERIOR RUANG PUBLIK
}

\author{
Ulli Aulia Ruki; Amarena Nediari \\ Interior Design Department, School of Design, BINUS University \\ Jln. K.H. Syahdan No. 9, Palmerah, Jakarta Barat 11480 \\ uruki@binus.edu; anediari@binus.edu
}

\begin{abstract}
Signage system is applied in interior public spaces with consideration to the basic of typography. The objective of signage system is to provide the user convenience in public spaces in order to reach destination while the user is in the building. The basic requirements for designing signage system are legibility and readability. There are still designers who are not aware about the importance of designing a signage system so that sometimes it is found only as decorative element. It is necessary to make the best use of the purpose of signage design, so an interior design should be more carefully in conducting research related to the application of signage system in public spaces. The applied typography has to be considered by its size, placement, colors, and materials to be used. This research used design thinking goal grid method that is suitable to examine the signage system in order to complete design objectives. Article focuses on how to design the signage system to accommodate information that was useful for the user in public space. At the end, there would be identified signage system's function in interior public spaces as information, guidance, identification as well as safety regulation.
\end{abstract}

Keywords: signage system, public spaces and typhography

\begin{abstract}
ABSTRAK
Sistem signage diaplikasikan pada sebuah interior ruang publik dengan memerhatikan dasar tipografi. Manfaat signage adalah memberikan kemudahan para pengguna ruang publik dalam mencapai tujuan saat mereka berada di dalam sebuah bangunan. Hal mendasar yang perlu diperhatikan dalam merencanakan sistem signage adalah kejelasan bentuk huruf serta kemudahan untuk dibaca. Masih banyak desainer yang kurang memerhatikan desain signage, sehingga terkadang desainnya memberikan kesan hanya sebagai elemen dekoratif. Dalam upaya memaksimalkan fungsi desain signage, sebaiknya seorang desainer interior melakukan penelitian dengan lebih saksama terkait dengan penerapan sistem signage khususnya pada ruang publik. Pemilihan jenis tipografi yang diterapkan perlu mempertimbangkan ukuran yang baik, peletakan yang tepat, pemilihan warna serta material yang akan digunakan. Penelitian menggunakan metode design thinking goal grid, yaitu metode yang cocok untuk mencari jawaban yaitu menentukan hal yang akan dicapai dalam tujuan mendesain. Diharapkan, artikel dengan topik mendesain sistem signage dapat memberikan informasi bagi pengguna ruang publik dengan baik. Pada akhir tulisan dapat dilihat cara membuat sistem signage, sehingga sistem signage ini dapat berfungsi dengan baik dalam sebuah interior ruang publik sebagai informasi, petunjuk, identifikasi, serta keselamatan dan regulasi.
\end{abstract}

Kata kunci: tipografi, sistem signage, ruang publik 


\section{PENDAHULUAN}

Kalimat "Design is not about how it looks like and feels like. Design is how it works" (Blumenthal, 2012) disampaikan oleh Steve Jobs dalam menyampaikan gagasannya akan pemahaman terhadap sebuah karya desain. Desain sebagai hasil dari sebuah gagasan pikiran menghasilkan sebuah karya berguna bagi manusia. Gagasan yang diungkapkan membutuhkan beragam media yang berbeda sehingga terbagi menjadi desain interior, desain produk, dan desain grafis. Secara keseluruhan desain berawal dari sebuah rancangan bentuk visual berupa gambar baik itu secara sketsa maupun gambar kerja. Bahasa gambar ini merupakan cara berkomunikasi seorang desainer dalam menerjemahkan ide maupun gagasannya ke dalam media yang ingin diciptakan.

Salah satu hasil kolaborasi antara desain grafis dan interior adalah peranan tipografi dalam desain interior khususnya pada ruang publik. Tipografi, yang pada awalnya diterapkan dalam media 2 dimensi, telah melalui perkembangan yang sedemikian pesat, sehingga banyak dijumpai dalam media ruang yang merupakan bidang 3 dimensi. Penerapan tipografi ini menjadi bagian dari perancangan sebuah desain interior khususnya pada interior ruang publik.

Signage merupakan bentuk visual 3 dimensi dalam penyampaian informasi pada sebuah fasilitas publik. Signage ini dapat ditemukan di jalan sebagai petunjuk arah, di luar gedung maupun di dalam area gedung. Setiap fasilitas publik memerlukan signage baik itu ruang museum, hotel, rumah sakit, stasiun, sekolah, perkantoran, pusat perbelanjaan, perpustakaan dan fasilitas lainnya. Berikut adalah beberapa gambar signage yang telah menyatu dalam perancangan sebuah desain interior.

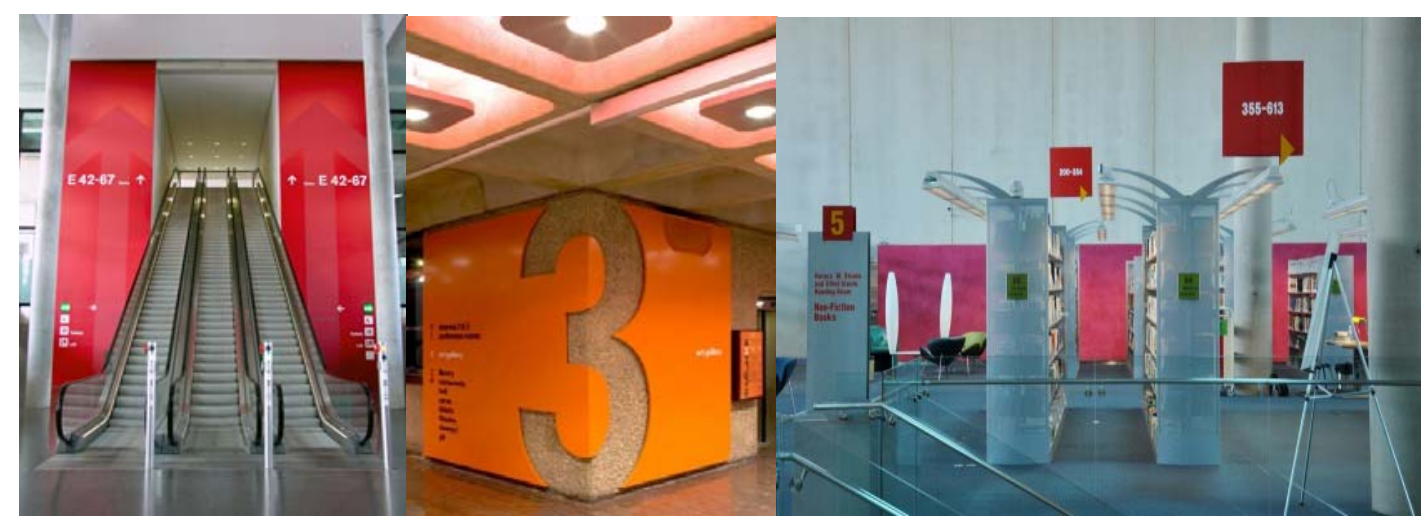

Gambar 1 Beberapa contoh signage yang ada di interior fasilitas publik

(Sumber: http://www.smashingmagazine.com)

Hasil dan manfaat yang diharapkan melalui penulisan ini adalah memberikan gambaran bahwa para desainer, baik itu desainer interior maupun desainer grafis, dapat bekerja sama dalam mendesain untuk keperluan publik. Selain itu, penggambungan konten materi tipografi dengan interior signange dapat menghasilkan pengayaan ilmu terapan yang membantu para desainer dalam mengambil keputusan desain, baik ukuran, warna, jenis huruf, serta peletakannya dalam sebuah interior. 


\section{METODE}

Dalam penulisan ini, penelitian menggunakan metode design thinking. Menurut Curedale (2013), metode ini dapat digunakan dalam kolaborasi dari berbagai ilmu. Metode ini mengombinasikan analisis dan berpikir kreatif dalam pendekatan terhadap pasar dan perilaku konsumen. Lebih dalam lagi, design thinking yang dipakai adalah skema goal grid, yaitu metodologi untuk menjelaskan tujuan yang ingin dicapai, dihindari, dipertahankan, dan dieliminasi. Berikut adalah diagram dari pemikiran dalam penelitian ini.

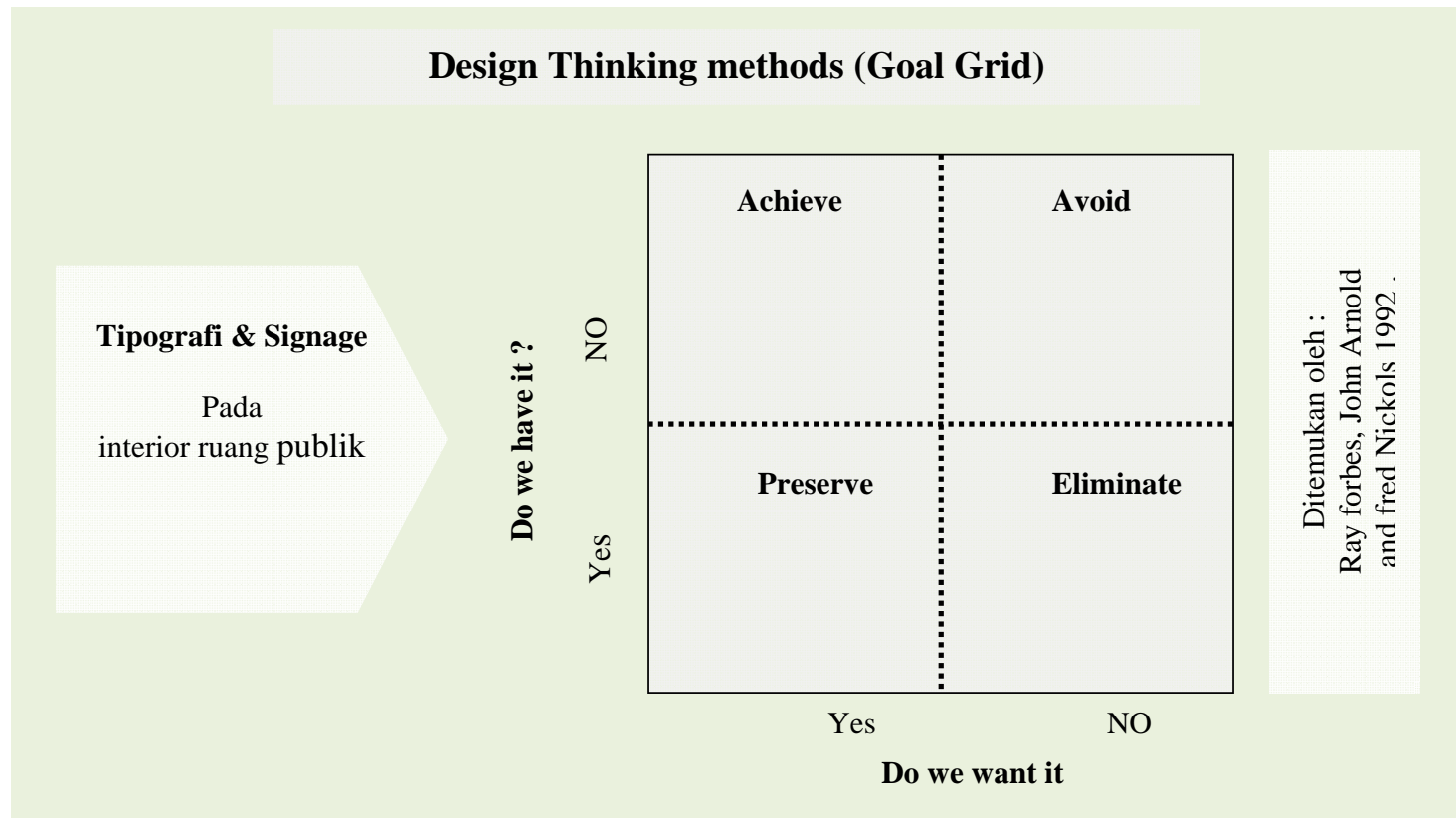

Gambar 2 Metode Design Thinking (Goal Grid)

Dari gambar, dapat dijelaskan hal apa saja yang harus diperhatikan dalam mendesain sebuah signage, baik dalam dimensinnya, pemilihan warna, pemilihan tempat pemasangan, jenis dan ukuran tulisannya. Ada baiknya dalam mendesain signage juga dikombinasikan dengan ilmu lainnya seperti desain komunikasi visual, khususnnya dalam bidang ilmu tipografi

\section{HASIL DAN PEMBAHASAN}

Tipografi merupakan tata huruf, sebuah ilmu dalam memilih dan menata huruf yang penyebarannya akan menciptakan kesan tertentu sehingga membantu pembaca untuk mendapatkan kenyamanan membaca. Huruf memiliki perpaduan nilai fungsional dan nilai estetik (Sihombing, 2003). Penerapan huruf dalam sebuah media, harus memiliki kejelasan bentuk huruf (legibility) dan keterbacaan (readibility). Untuk kejelasan bentuk huruf maksudnya adalah mengenali karakter huruf tanpa harus bersusah payah.

Hal ini ditentukan oleh kerumitan huruf, penggunaan warna, serta frekuensi pembaca dalam menemukan huruf dalam kehidupan sehari-hari. Sementara untuk keterbacaan yang dimaksud adalah kemudahan suatu susunan huruf saat dibaca yang ditentukan oleh jenis huruf, ukuran, pengaturan spasi serta kontras warna terhadap latar belakang). Adanya dua ketentuan di atas tadi menjadi dasar pertimbangan yang perlu diperhatikan pada saat menggunakan tipografi dalam sebuah desain interior. 
Dalam mempelajari tipografi yang perlu diketahui adalah mengenali dan memahami anatomi huruf. Seperti halnya manusia huruf memiliki berbagai organ yang berbeda. Terminologi yang umum digunakan dalam penamaan setiap komponen huruf adalah baseline, capline, meanline, $x$-height, ascender, dan descender (Gambar 2).

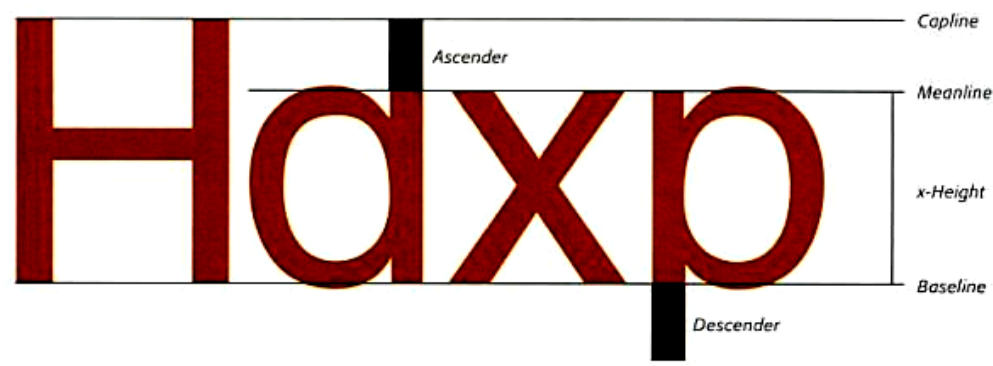

Gambar 3 Komponen Huruf dalam Ilmu Tipografi

Ciri dari sebuah huruf yang mudah dikenali adalah melalui goresan (stroke), siripan (serif) dan sempitan (stress) Garis pembuka dan penutup dari stroke disebut serif dan huruf yang tidak memiliki serif (siripan) disebut dengan san serif. Dalam teori Gestalt tentang hukum persepsi, huruf memiliki dua ruang dasar, yaitu figure sebuah ruang positif dan ground sebuah ruang negatif (terdiri atas ruang negatif bersudut lengkung, bersudut segi empat dan bersudut segi tiga) (Sihombing, 2003).

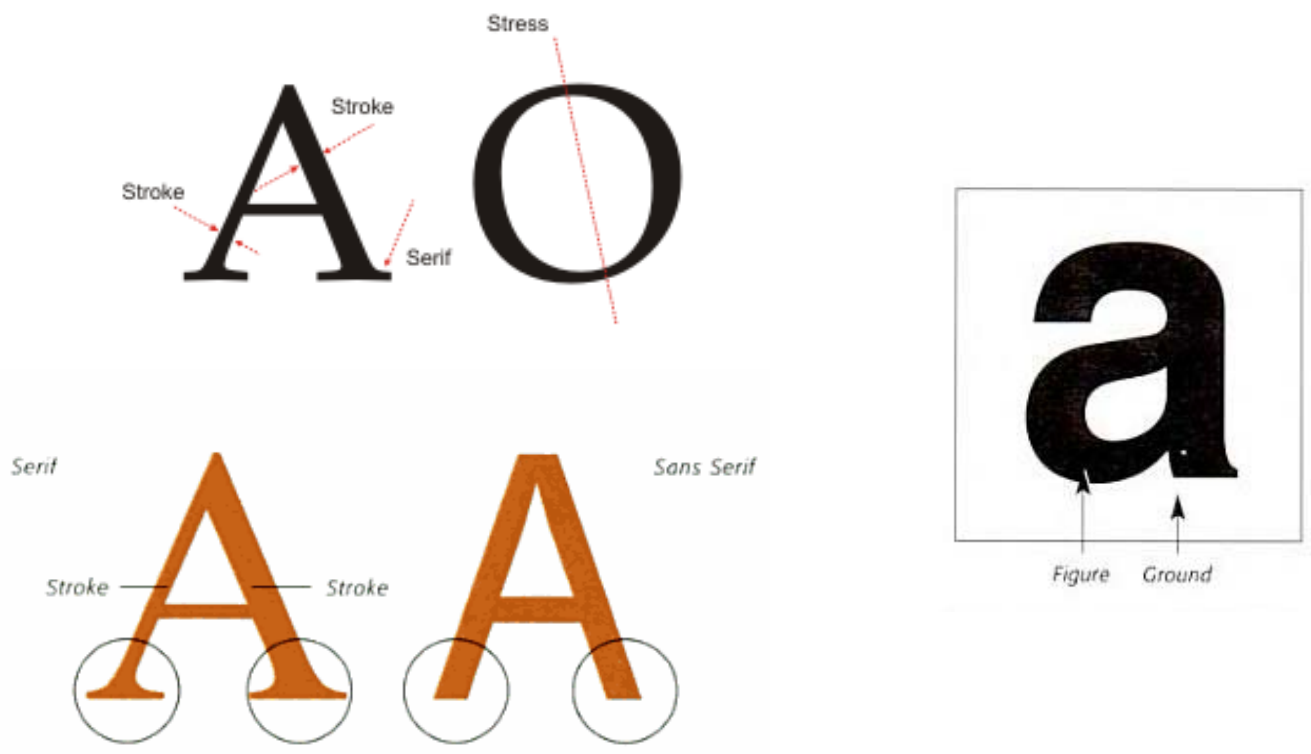

Gambar 4 Goresan, siripan dan sempitan pada sebuah huruf (Sumber: http://id.wikipedia.org/wiki/Berkas:AOcirihuruf.png)

Gambar 4 merupakan penjelasan bahwa pemilihan jenis huruf dapat disesuaikan. Karena adannya beberapa pemilihan perlakuan terhadap mendesain bentuk dari huruf, diharapkan keputusan desain terhadap pilihan huruf dapat tetap menjadi efektif. Agar tipografi tetap efektif, Strizver (n.d.) menyebutkan bahwa ada beberapa pertanyaan penting sebelum mendesain huruf. Berikut adalah beberapa pertanyaannya yang sebaiknnya digunakan. 


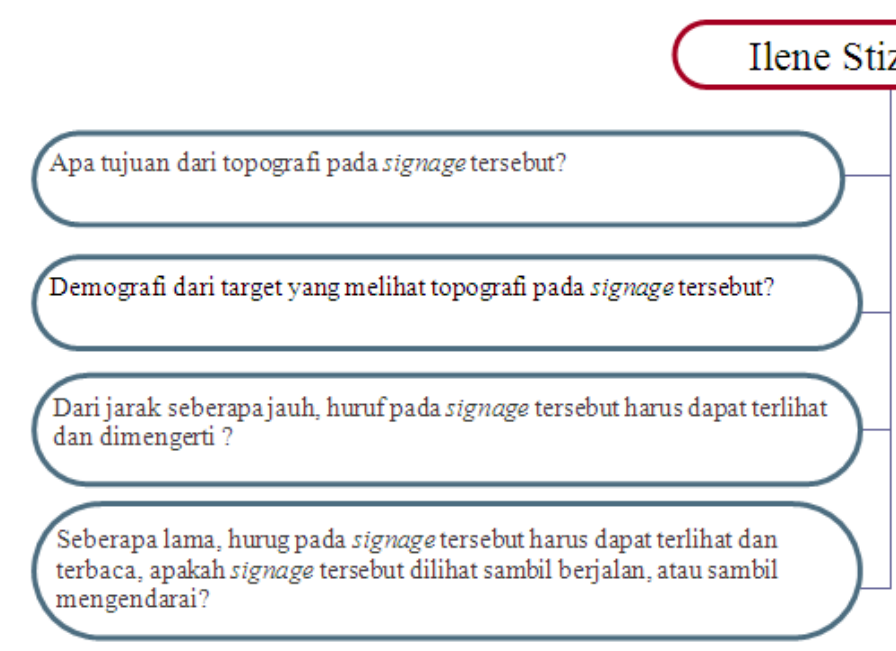

Gambar 5 Pertanyaan sebelum Mendesain Huruf

(Strizver, n.d.)

Dengan beberapa pertimbangan yang telah disampaikan, dan mengetahui tentang tipografi secara umum, berikut adalah penjelasan mengenai signage secara singkat serta peletakannya yang dianjurkan dalam beberapa sumber terkait agar informasi yang dibentuk dapat menjadi satu paket desain yang utuh.

\section{Signage}

Signage dapat berbentuk dalam rupa yang beragam. Signage dapat diletakkan di jalan (landscape), di luar gedung (exterior), dan di dalam gedung (interior). Menurut Signbox (n.d.) jenis dari signage dapat dikategorikan berdasarkan fungsi, desain, dan juga material finishing yang digunakan. Contoh sigange yang sering diaplikasikan dalam sebuah interior adalah signage logo, ikon perusahaan, signage untuk menunjukkan jalan, signage untuk keselamatan (safety), signage untuk proyeksi desain khusus dan untuk keperluan yang mudah terlihat seperti di area terbuka (open plan layout). Signage lainnya yang didesain khusus adalah signage yang menggunakan huruf timbul (braille dan tectile). Signage yang didesain secara modular (modular sign system) agar memudahkan sisitem pergantian dan juga memindahkan penamaan ruangan yang biasannya dipakai untuk sistem organisasi yang fleksibel. Serta signage dengan jenis penambahan pencahayaan lampu (LED Iluminated signs)

\section{Kategori Signage}

Dalam penelitian sebelumnya, telah disampaikan pengategorian signage pada jalan raya ada 5 , yaitu Oriental Signage, Informational Signage, Directional Signage, Identificational Signage, Stationary Signage, Ornamental signage (Puspitasari \& Darmawan, 2013). Sementara pada interior ruang publik, klasifikasi pembuatan signage dapat dikategorikan menjadi empat bagian (Gibson, 2009) yaitu sebagai berikut.

Pertama, signage sebagai penunjuk arah (guidance), mengarahkan seseorang atau pengunjung untuk menuju ruangan yang diinginkan. Biasannya peletakan signage untuk menunjukkan arah dari mulai pintu masuk, di dalam ruangan sampai dengan pengunjung berada kembali diluar interior fasilitas tersebut. Beberapa contoh penerapannya dapat diletakkan di lantai, di ceiling, dan juga di dinding. Signage petunjuk ini harus dapat mudah terlihat dan juga dapat dibaca secara cepat terutama petunjuk arah untuk keluar, petunjuk menuju tangga darurat, dan menuju akses vertikal dan horizontal. 


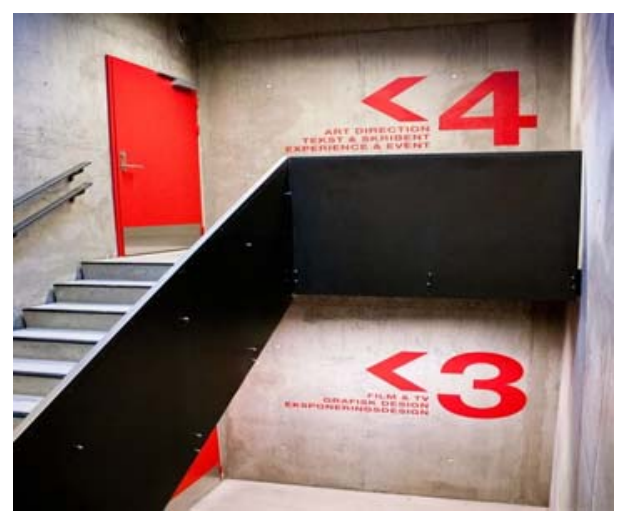

Gambar 4 Contoh Signage sebagai Penunjuk Arah

(Sumber: Desamba, 2012)

Kedua, signage sebagai petunjuk list ruangan (information). Signage tipe ini digunakan untuk mengurutkan nama yang ada pada fasilitas publik, apakah itu list ruangan, departemen, list perusahaan, ataupun list nama dokter praktik di dalam gedung. Selain informasi dari nama, biasannya juga disertai dengan nomor ruangan, ataupun lantai posisi ruangan berada. Mengenai ukuran standar biasanyan ketinggiannya tidak melebihi tinggi manusia yaitu sekitar 75-180 cm agar mudah dibaca. penempatannya bisa berdiri sendiri ataupun juga menempel di dinding interior. Lokasinya lebih baik diletakkan di beberapa tempat dan bagian yang sering mudah dicapai pada saat pertama kali datang.

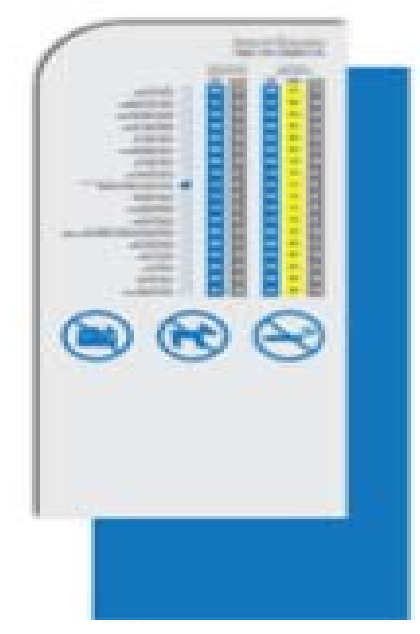

Gambar 5 Contoh Signage sebagai Penunjuk Arah

(Sumber: Tungtrongsitt, 2013)

Ketiga, signage sebagai identifikasi kategori ruangan (identification). Maksud dari identifikasi departemen adalah sebagai pemberi informasi kepada pengunjung mengenai kategori ruang atau area berada secara umum, seperti pembagian area di kantor, rumah sakit, dan pusat perbelanjaan. Sebagai contoh adalah penerapan identifikasi departemen yang berlaku di pusat perbelanjaan seperti pembagian berdasarkan kategori produk yang dijual ataupun kantor yang memiliki banyak pembagian departemen di dalam organisasinnya. Sebagai contoh lainnya adalah informasi untuk pengunjung rumah sakit yang memerlukan informasi kategori area praktik dokter yang ada di rumah sakit tersebut, seperti Gambar 6 berikut. 


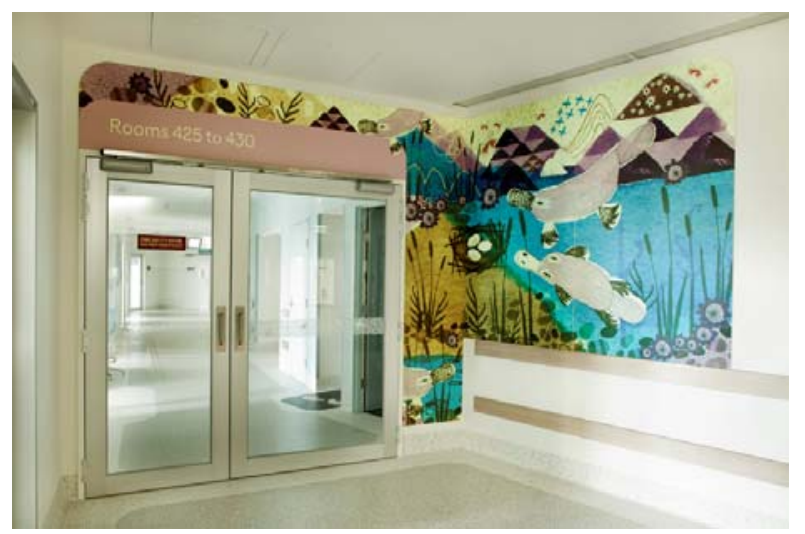

Gambar 6 Signage pada Royal Children’s Hospital Melbourne menunjukkan area kamar rawat 425-430 pada pintu masuknya

(Sumber: Powerhouse Museum, 2012)

Selain sebagai signage, tipografi sebagai unsur dekoratif dapat diterapkan dengan lebih leluasa. Hal itu disebabkan tujuan dari dekoratif adalah untuk menambah nilai estetis pada sebuah ruang publik. Adanya tipografi pada dinding sebuah interior ruang publik, sering kali memberikan pernyataan yang memberikan perbedaan antara fungsi satu ruang dengan ruang lainnya.

Keempat, signage sebagai identifikasi nama ruangan (safety regulation).Untuk semua ruangan yang berada dalam fasilitas publik ada baiknya diberikan nama dan nomor. Selain itu juga keterangan diberikan apakah ruang tersebut adalah ruangan yang boleh diakses publik atau hanya pegawai. (Lihat Gambar 7)

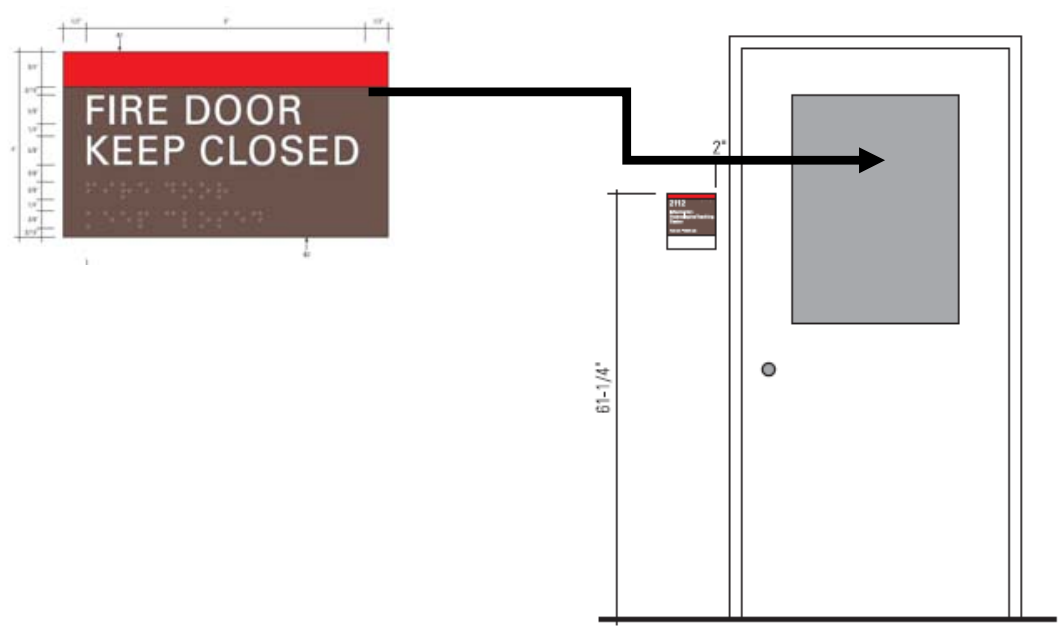

Gambar 7 Contoh Signage yang diletakkan menempel pada pintu atau disebelahnnya

(Sumber: U.S. Department of Veterans Affairs, 2012) 


\section{SIMPULAN}

Pertama, perihal yang harus didapatkan (achieve). Peletakan signage yang baik dan benar dan juga tulisan yang digunakan dapat terlihat, terbaca secara baik. Berikut adalah contoh gambar konfigurasi peletakan signage pada interior fasilitas publik. Gambar dimulai dengan peletakan signage directories, direction, room identification dan juga department identification.

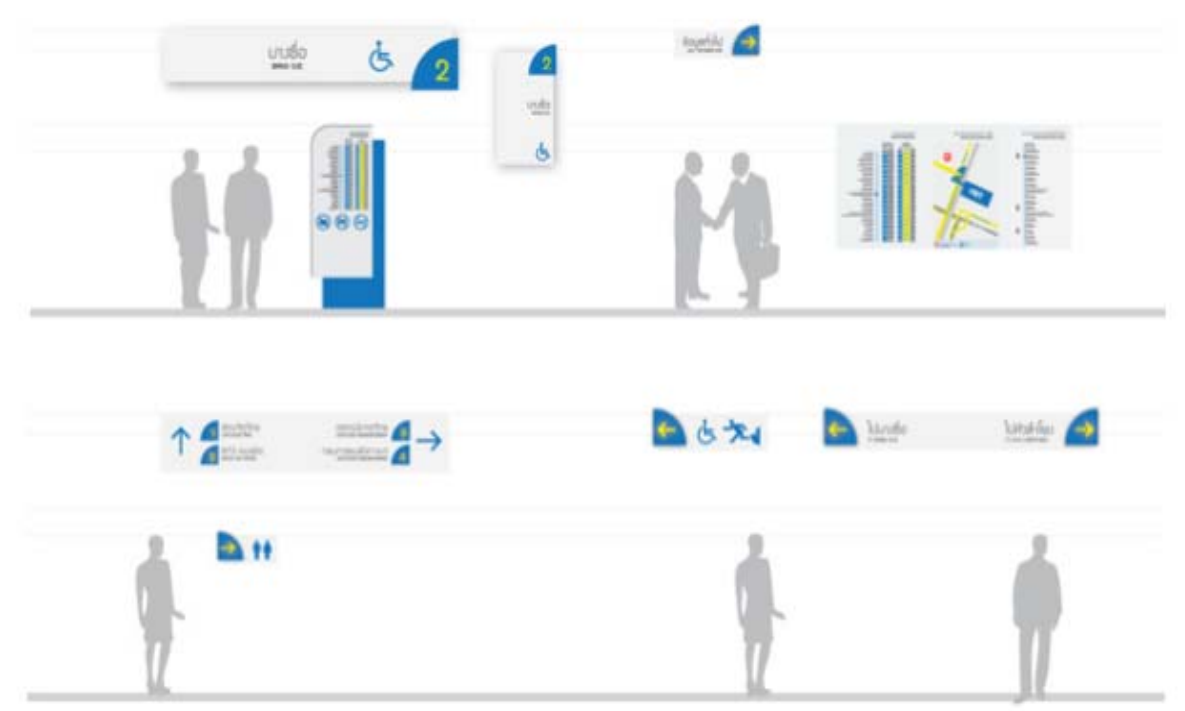

Gambar 8 Konfigurasi Peletakan Signange pada Berbagai Posisi di Ceiling

(Sumber: Tungtrongsoitt, 2013)

Ketinggian dimensi peletakan signage yang sesuai dengan segala keadaan kondisi pengunjung, baik pengunjung yang memiliki keterbatasan seperti memakai kursi roda, keterbatasan dalam melihat terutama manula. Hal ini juga menjadi suatu ketercapaian untuk signage yang baik, yaitu dengan mengevaluasi kembali pada saat interior fasilitas tersebut sudah berfungsi dengan benar, baik dalam terlihat, terbaca, dan juga berfungsi.

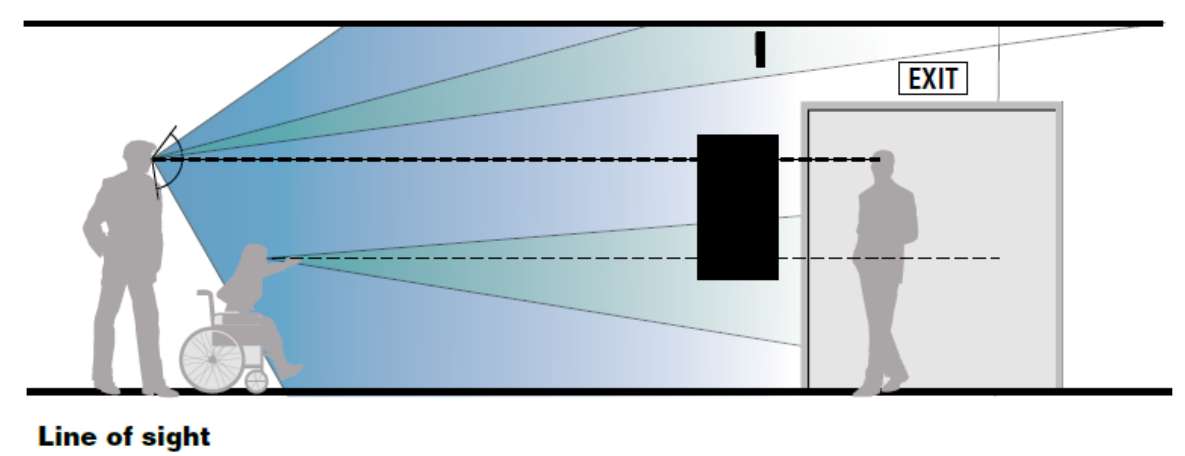

Gambar 9 Konfigurasi Peletakan Signange di Dinding

(Sumber: US Department of Veterans Affairs, 2012) 
Selain pelatakannya, finishing pada signage sebaiknnya juga menjadi perhatian. Signage bisa menjadi sangat mendukung konsep jika dapat memadukan antara warna dan material yang sesuaikan dengan konsep warna logo perusahaan tersebut.
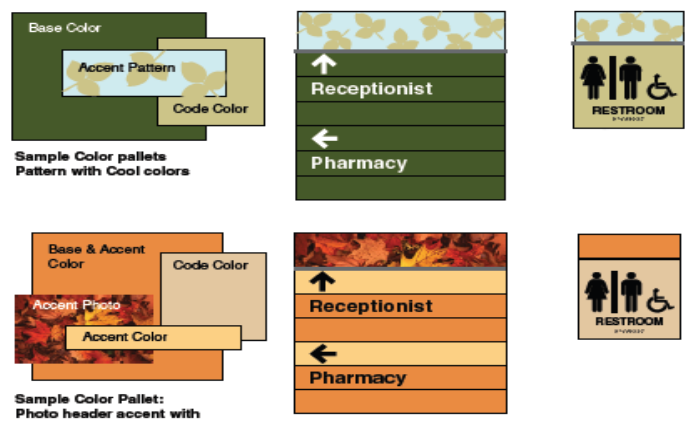
Sample Color Pallet:
Photo header accent with
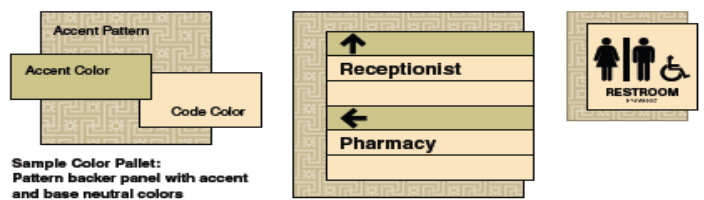

Gambar 10 Konfigurasi Peletakan signange di dinding (Sumber: Strizver, n.d.)

Dari gambar dapat dilihat perpaduan warna dan tekstur sebuah pola dapat disesuaikan agar mendapatkan efek ruang yang seragam atau setidaknnya mempunyai garis merah kesinambungan pada semua ruangan interior.

Kedua, perihal yang harus dihindari (avoid). Diharapkan, para desainer atau mahasiswa yang belajar desain Interior dapat meminimalkan kesalahan pada setiap keputusan desain dan memaksimalkan kepuasan yang dirasakan oleh pengguna interior tersebut. Desiner diharapkan untuk menghindari tipe dengan latar belakang yang ramai. Hal ini menyulitkan untuk membaca tulisan dengan cepat. Selain itu, hindari godaan untuk menggunakan gimik atau ilustrasi yang pada tulisan yang berlebihan. (lihat Gambar 11)
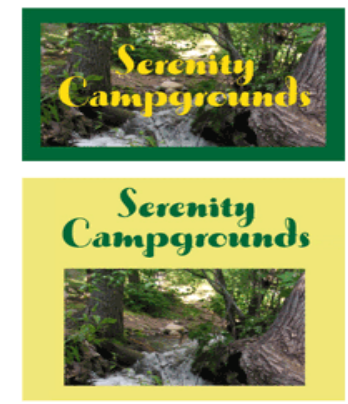
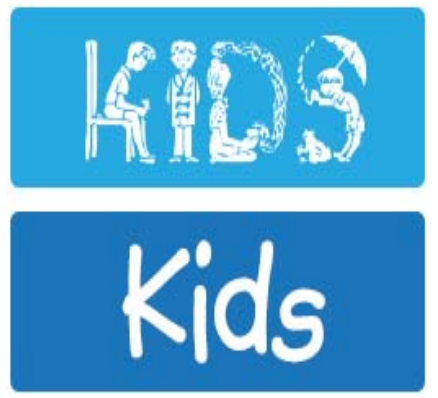

Gambar 11 Design Signage yang Harus Dihindari

(Sumber: Strizver, n.d.)

Ketiga, perihal yang harus dipertahankan (preserve). Mempertahankan gambar atau simbol dengan tulisan akan lebih baik. Simbol dan tulisan membantu kecepatan bagi yang melihat untuk mendapatkan informasi, terutama pada saat berjalan. 


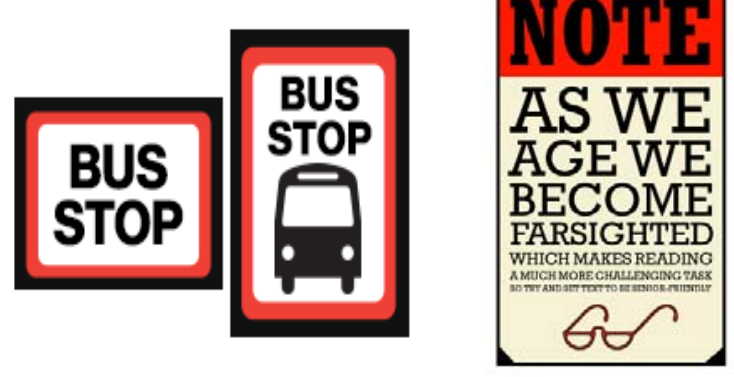

Gambar 12 Design Signage yang Harus Dipertahankan

(Sumber: Strizver, n.d.)

Ditambah lagi, mempertahankan besaran tulisan sangatlah penting. Banyak fasilitas juga didatangi juga oleh para senior yang mungkin lebih baik memberikan tulisan yang mudah dibaca walau tanpa kacamata.

Keempat, perihal yang harus dieliminasi (eliminate). Eliminasi tulisan yang menyulitkan untuk dibaca; atau gunakan tulisan yang tidak terlalu banyak paragraf (Gambar 13). Eliminasi warna tulisan yang tidak membuat kontras dengan background (Gambar 14). Eliminasi tulisan yang terlalu rapat agar mudah dibaca sesuai dengan yang ada (Gambar 15).

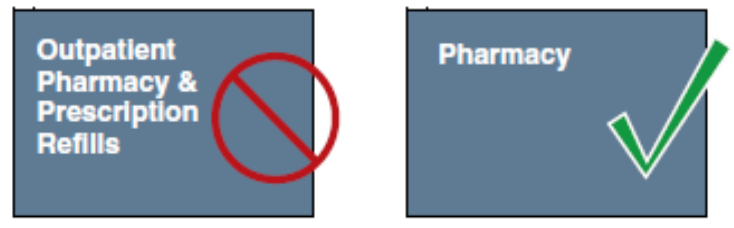

Gambar 13 Hilangkan Tulisan yang Sulit Dibaca/ Terlalu Banyak Paragraf
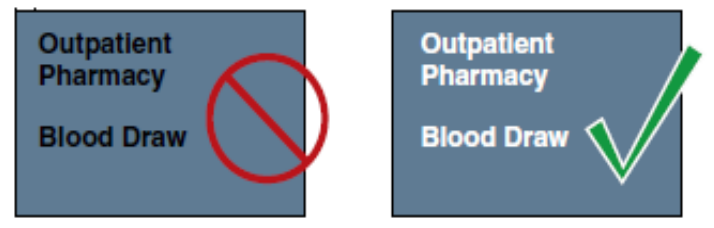

Gambar 14 Hilangkan Tulisan yang Tidak Kontras dengan Background

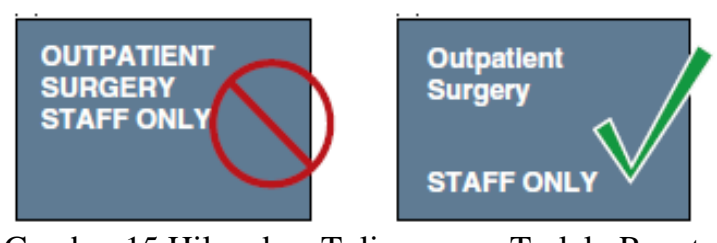

Gambar 15 Hilangkan Tulisan yang Terlalu Rapat

Dengan demikian, penjelasan diharapkan dapat membantu untuk mengetahui perihal apa saja yang harus diketahui pada saat mendesain tipografi dan menerapkan sistem signage pada sebuah interior. 


\section{DAFTAR PUSTAKA}

Blumenthal, K. (2012). Steve Jobs, The Man who Think Different. USA: Bloomsbury.

Curedale, R. (2013). Design Thinking: Pocket Guide. Design Community College.

Desamba, Y. (2012, 14 Desember). 40 Awesome Signage/Wayfinding \& Environmental Designs Inspiration. Diakses dari http://jayce-o.blogspot.com/2012/12/awesome-signage-wayfindingenvironmental-designs.html

Gibson, D. (2009). The Wayfinding Handbook; Information Design for Public Spaces. New York: Princeton Architectural.

Powerhouse Museum. (2012). Royal Children's Hospital Melbourne. Diakses dari http://www.dhub.org/wp-content/uploads/2012/12/MG_6062.jpg

Puspitasari, D. G., dan Darmawan, J. (2013). Signage dan penerapannya: lingkungan jalan raya tol Bintaro. Humaniora, 4(1), 475-490.

Signbox (n.d.). A Range of Interior Signage Solutions. Diakses 27 Mei 2014 dari http://www.signbox.co.uk/interior/interior

Sihombing, D. (2003). Tipografi dalam Desain Grafis . Jakarta: Gramedia Pustaka Utama.

Strizver, I. (n.d.). Typography for Signage. Diakses 25 Mei 2014 dari http://www.fonts.com/content/learning/fyti/situationaltypography/typography-for-signage

Tungtrongsitt, S. (2013, 2 Agustus). MRT: Signage System. Diakses 25 Mei 2014 dari https://www.behance.net/gallery/MRT-Signage-System/10171965

US Department of Veterans Affairs. (2012, Desember). Interior Signs. Diakses 25 Mei 2014 dari http://www.wbdg.org/ccb/VA/VASIGN/signage09.pdf 